\title{
Stress Analysis of Thoracolumbosacral Orthosis (TLSO) for Scoliosis deformity and its Effects on Gait Cycle
}

\author{
Fahad M. Kadhim ${ }^{1 *}$, Sara I. Ahmed ${ }^{2}$
}

\section{Authors affiliations: \\ 1) Prosthitic and Orthotics Engineering Department, University of Al-Nahrain Baghdad-Iraq. fahadmohanad@gmail.com}

2) Ministry of Health, BaghdadIraq.

\section{Paper History:}

Received: $10^{\text {th }}$ April 2019

Revised: $10^{\text {th }}$ June 2019

Accepted: $17^{\text {th }}$ Sep. 2019

\begin{abstract}
This work involved two major parts: the first one is the experimental part which included treatment of scoliosis deformity by manufacturing thoracolumbosacral orthosis, measuring the cobb angle of deformity, measuring the gait cycle data and walk path for both legs and suggesting a composite material to improve the mechanical properties of the orthosis and finally the interface pressure between trunk and orthosis is measured for twelve points covering of the total TLSO surface area by using $f$ socket devise. The second part of this study is the numerical simulation part during which the stresses are calculated using Ansys software for calculating stresses due to interface pressure loading boundary condition. The result shows no deference in gait cycle phases but the clear difference noted in walking path due to deviate center of mass, maximum pressure recorded left thoracic region with $900 \mathrm{KPa}$ due to correct spinal deformity while the minimum pressure recorded at right chest with $140 \mathrm{KPa}$ because of it is tissue region and Maximum value of stress was recorded at the left thoracic region with $2.81 \mathrm{MPa}$ due to Maximum interface pressure at this point.
\end{abstract}

Keywords: Orthosis, Scoliosis, Gait Cycle, Thoracolumbosacral, Cobb Angle.

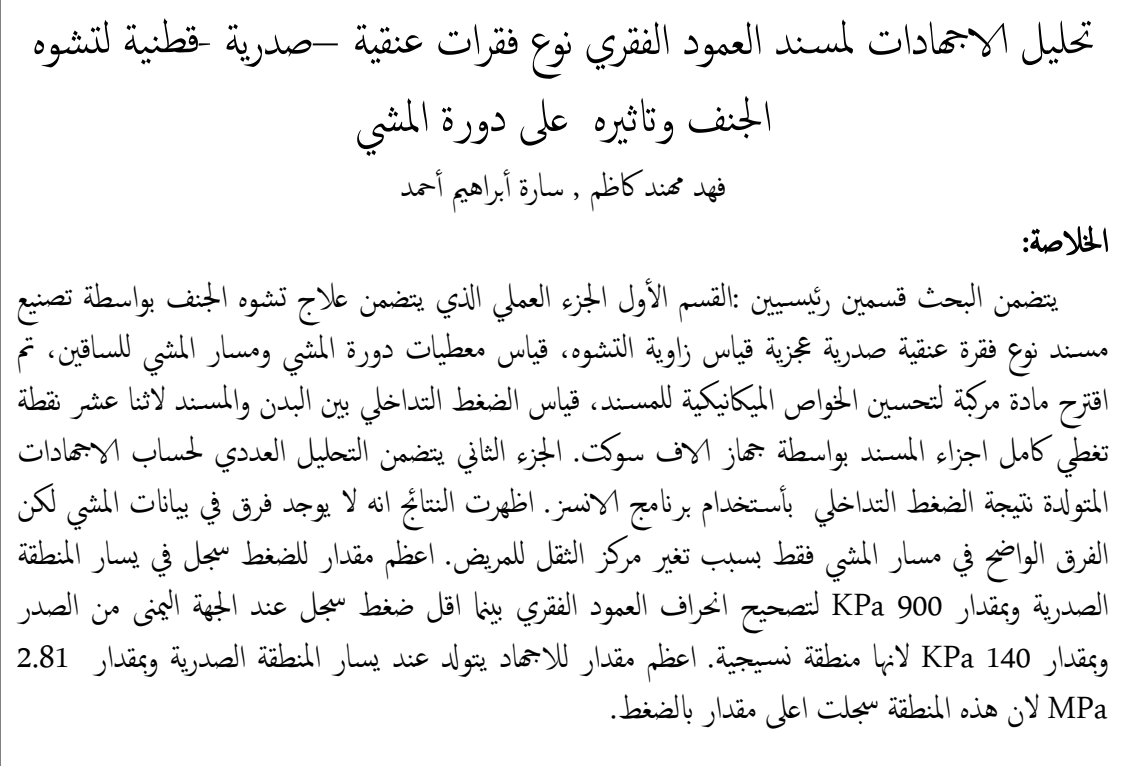

plane, resulting in rounding of the shoulders and an inwards curvature in the lower back, scoliosis typically involves a deformity of the spinal column and rib cage that causes deformity in three dimensions [3]. The spine curves sideways, and some of the spinal bones may rotate slightly, causing unevenness of the hips or shoulders [4]. Scoliosis is classified according to its etiology, patient age at onset, direction, location and magnitude. A spine with a typical scoliosis shown in Fig. (1) presents an S or $\mathrm{C}$ shape, rather than a straight line, when viewed 
from behind. Scoliosis is defined as an abnormal curvature of the spine measuring 10 degrees or greater [5].

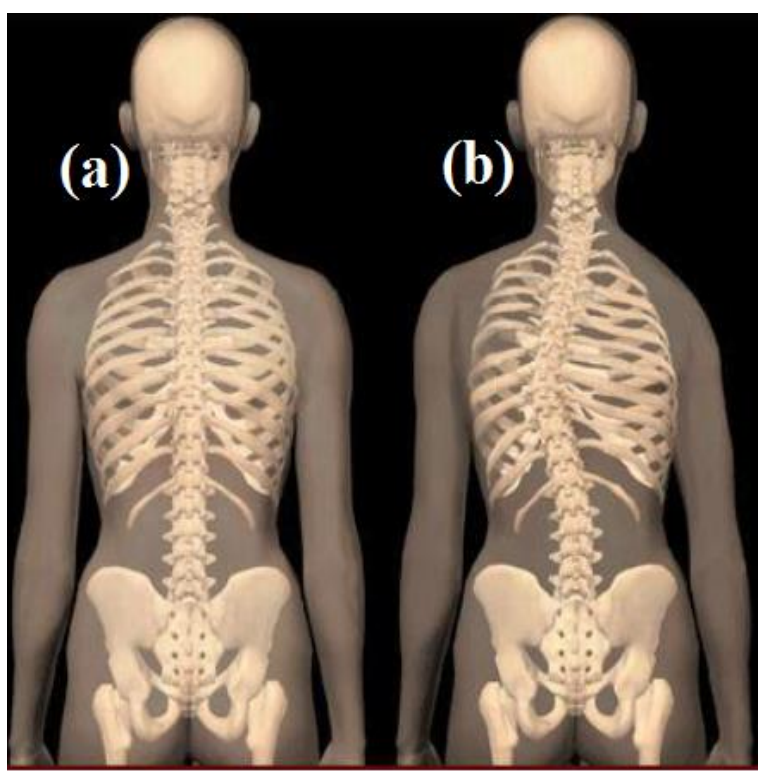

Figure (1): (a) A normal spine, and (b) a spine with scoliosis.

Patients with stable spinal fractures or deformities such as idiopathic scoliosis often have to wear orthoses as part of their treatment. Such orthoses typically apply sustained forces to the trunk and pelvis in order to immobilize one or more motion segments of the spine [6] or apply corrective bending and/or torsional moments [7].In this study three points pressure will be applied on the spine by dressing thoracolumbosacral orthosis (TLSO) and these forces are opposite in direction so as to correct and reduce the deformity. to apply correction force in the optimal location and to achieve treatment faster $\mathrm{X}$-ray is taken for the patient with based on the $\mathrm{x}$-ray image, the position of applied three points pressure and direction are identified. In this research, the deformity is treated in a mechanical manner that prevents its progress because the continuous deformation may only be treated by surgery. In addition, correction of deformity leads to restoring the balance of the body and preventing its deviation during walking due to the deviation of the center of the body mass. The principal of the three points pressure system is utilized in spinal orthotics a three points pressure system can be used independently or combined with opposing three point pressure systems to give circumferential support immobilization and correction deformity Fig.(2) shows an example of a three point pressure system acting on the spine in a spinal orthosis.

\section{The Experimental part included:}

Experimental work was done on a case study suffering from Scoliosis deformity with age: weight and length of 14 years $45 \mathrm{~kg}, 150 \mathrm{~cm}$ respectively.

\subsection{Cobb Angle Measurement:}

The value of scoliosis deformity is measured by taking X-RAY from the front side of the patient. For measurement when assessing a curve the apical vertebra is first identified. This is the most likely displaced and rotated vertebra with the least tilted end plate. The end/transitional vertebra are then identified through the curve above and below. The end vertebra is the most superior and inferior vertebra which are least displaced and rotated and have the maximally tilted end plate. A line is drawn along the superior end plate of the superior end vertebra and a second line drawn along the inferior end plate of the inferior end vertebra. The angle between these two lines or lines drawn perpendicular to them is measured as the Cobb angle as shown in Fig. (3).

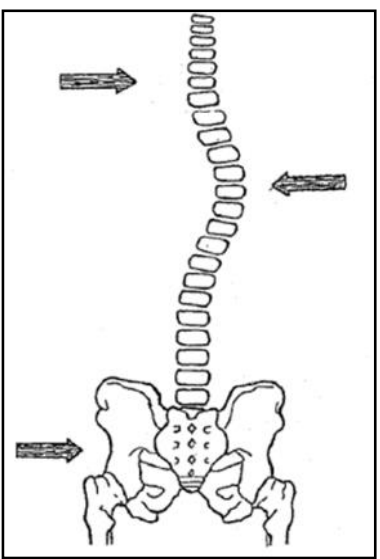

Figure (2): point pressure system required to correct

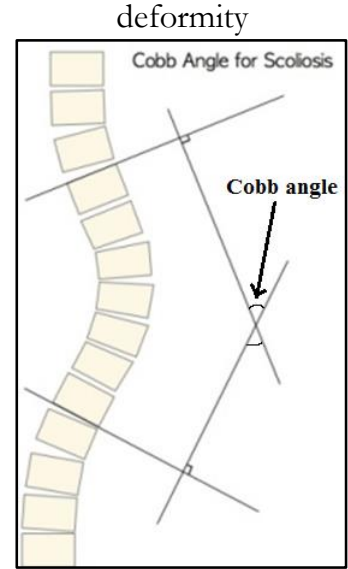

Figure (3): Cobb angle of spinal deformity.

\subsection{Manufacturing of the spinal orthoses:}

2.2.1. Selected material for the manufacture of the orthosis:

The material chosen for the manufacture of the TLSO is polypropylene because it is lightweight, strong, flexible and does not react chemically to the skin [8].

Table (1): The mechanical properties of standard polypropylene [9].

\begin{tabular}{|c|c|c|c|}
\hline $\begin{array}{c}\text { Young's } \\
\text { Modulus }\end{array}$ & $\begin{array}{c}\text { Density } \\
\left(\mathbf{k g} / \mathbf{m}^{\mathbf{3}}\right)\end{array}$ & Yield Stress & $\begin{array}{c}\text { Ultimate } \\
\text { Stress }\end{array}$ \\
\hline $1.24 \mathrm{Gpa}$ & 890 & $27.2 \mathrm{MPa}$ & $37.3 \mathrm{MPa}$ \\
\hline
\end{tabular}

2.2.2 Patient interview/patient assessment to determine history injury, functional losses, patient goals, and orthotic requirements. Equipment preparation: Rolls of plaster, cotton sock / stockinet for the trunk, rope of cotton from the cotton sock (to modify the waist area/iliac crest),tape measures, 
caliper measures, indelible pencil, measure chart/patient assessment form, cast scissor, knife, plastic - tube / cut-off strip. Dressing the cotton sock / stockinet on the patient then marking the landmarks at the Inferior edge of the scapula, Superior angle of the scapula, Xiphoidal process, umbilicus. distal margins of the ribs. Pubic symphysis and greater trochanter of the femur. The following measurements are taken according to the measurements charts Fig. (4). Circumference waist, Diameter at the waist with some compression, Circumference at the level of xiphoid process, Diameter at level of xiphoid process, Circumference at the level of pubic symphysis, Diameter at the level of pubic symphysis, Circumference at the greater trochanter area, Diameter at the greater trochanter level, Distance between left and right ASIS, Diameter at the widest part of the iliac a crest, Distance between xiphoid process and pubic symphysis.

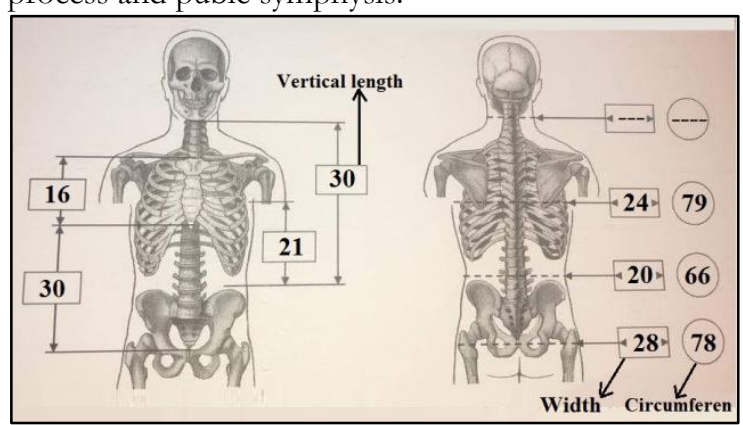

Figure (4): Measurements charts in cm unit.

After that casting the mold In this part the patient is standing position with circumferential plaster cast. The following steps should be taken to ensure a starting cast is taken, having a person to assist, and talk through the casting before starting with the patient and your assistant then positioning the plastic tube so as not to harm the patient when using a cuter for removing the plaster cast.After that tacking a circumference cast approx. 4-6 layers of plaster of pairs. Making sure that the postural position of the patient is correct by no lateral trunk bending, no rotation of the trunk, no excessive kyphosis, not too much hyper lordosis (unless you want a hyper lordosis orthosis) and remember that the lordosis decrease when the patient is sitting. Before the plaster to be set applied three point pressure at the casting for correct the spinal deformity. Three-point pressure points are applied by hand-pressing on the plaster before it dries where the hand is pressed on the deformation correction zones.Drawing the trim lines on the orthosis then removing the cast by cutting the cast by scissors or a knife with a cut- off strip / tube. Assisting the patient with cleaning and dressing.

Processing before put plaster and doing the following:

- Linking the cast.

- Lower aperture is adjusted and closed by plaster of Paris.

Then Putting Vaseline oil to facilitate the separation of plaster of Paris and model Cast process and ensure the cast is sitting in perpendicular position. Filling the negative cast with plaster.

Preparing of Rectification
- Putting the rod and wait for solidifies after 2 hour and fixing on Menken.

- Removing the negative plaster Paris from the mold.

Then rectification the mold with the following steps

- Cleaning-up cast by removing any small

imperfections (wrinkle marks) the stockinet may have caused.

- Reducing the casting area over stomach $\backslash$ breasts.

- Reducing the casting area over fleshy 'bulges around lateral belly area to create a smooth lateral wall -shape.

- Reducing the supra -iliac areas for suspension [NBbe careful to avoid the ASIS region and iliac crest during this reduction].

-If required, build-up the gypsum over the ASIS area and prominent rib areas to prevent the hard contact between the bones and orthosis.

After finished the rectification process, the draping of the plastic can be done either under suction or without suction (and 'rubbed in using powder and woolen gloves).If it is available, and if it is required, a foam lining can be mounded initially before the plastic is mounded. Alternatively, pads can be placed in the cast either prior to molding, or during manufacture, to support areas such as the supra - iliac suspension or protection over ASIS area. Cutting the draping mold by oscillating saw according the trim line of the orthosis with grading and soften the edges of the orthosis. Putting the pads in in the inner surface of the orthosis to increase the values of pressure applied in the three points pressure areas then fixing the strips on the orthosis to tighten the orthosis on the trunk. Finally the orthosis is completed and begin already for using as shown in Fig. (5).

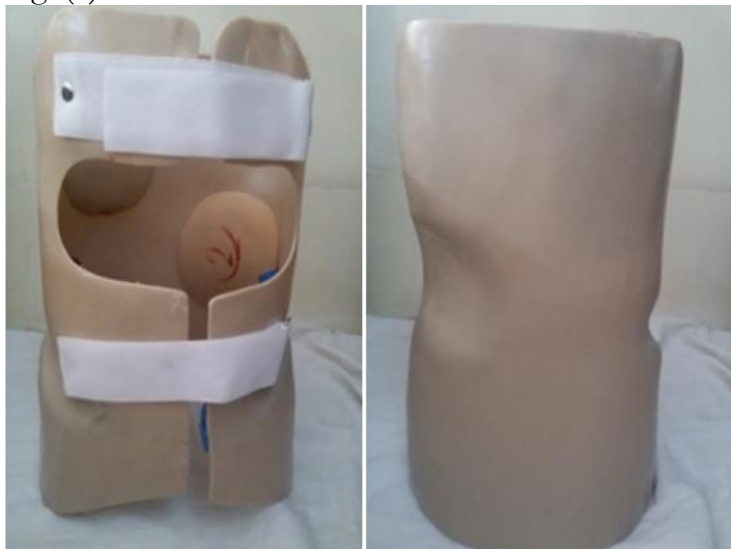

Figure (5): Final shape of TLSO

\subsection{Measuring Interface Pressure :}

When the patient dressing orthosis that cause to generate interface pressure between orthosis and the trunk as a result of the orthosis is squeezing trunk to correct scoliosis deformity. The interface pressure between trunk and orthosis is measured for nine points covering of the total TLSO surface area. The sensor type (Mat Scan) of piezoelectric is more acceptable for this type of dynamic load. The interface pressure was obtained by recording the output signal of the sensor through a multi-meter instrument which is interface with the computer and 
recording the data with the time. The specification of the F-socket sensor (pressure mapping sensor 3150) is inserted in the following table (2) [10].

Table (2): The specification of the F-socket sensor

\begin{tabular}{|l|l|}
\hline Overall Length & $600 \mathrm{~mm}$ \\
\hline Overall Width & $80 \mathrm{~mm}$ \\
\hline Tab Length & $300 \mathrm{~mm}$ \\
\hline Thickness & $0.102 \mathrm{~mm}$ \\
\hline Row Width & $5.8 \mathrm{~mm}$ \\
\hline Row Spacing & $8.4 \mathrm{~mm}$ \\
\hline Row Quantity & 44 \\
\hline Column Width & $5.8 \mathrm{~mm}$ \\
\hline Column Spacing & $8.4 \mathrm{~mm}$ \\
\hline Column Quantity & 52 \\
\hline Max Pressure & $862 \mathrm{KPa}$ \\
\hline
\end{tabular}

\subsection{Gait Cycle Test:}

This test achieved in two ways. First part by the patient dressing Thoracolumbosacral orthosis (TLSO) while second part without dressing orthosis. For each case patient was walked on force plate devise as shown in Fig. (6). The aim of repeated test in second try to get on data clarify the difference of walk path for patient when dressing orthosis and without orthosis and check the effect of the orthosis on correcting the walking path.

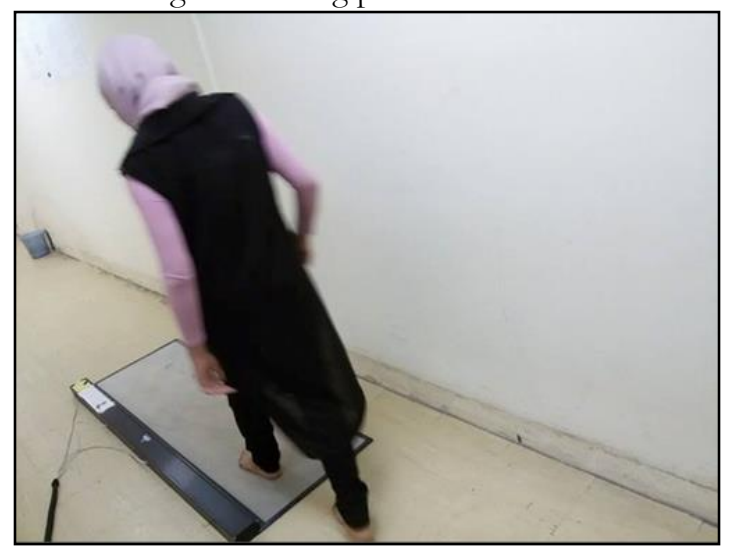

Figure (6): patient was walked on force plate devise

\subsection{Suggestions on a composite material}

In this study, a composite material consisting of 8 layers was suggested. These eight layers consist of ( two layers of Perlon +one layer fiber glass + two layers of Perlon + one layer fiber glass + two layers of Perlon) respectively. The material needed in lamination the following materials.

1-Perlon stockinet

2-Fiberglass stockinet

3-Lamination resin 80:20 polyurethane (proter hand icap technology).

4-Hardening powder.

5-Polyvinyalcohol PVA bag.

6- Materials for Jepson mold.

\subsubsection{Equipment}

- Jepson mold (positive mold rectangular cuboids in shape with size $10 * 10 * 24 \mathrm{~cm}^{3}$.

-vacuum forming system including vacuum pump and different types of stands, pipes and tubes.

-mechanical workshop including different types of cutting and forming and measuring machine.
- universal instrument machine test for tensile and flexural test.

\subsubsection{Procedure of lamination}

All laminations were performed under vacuum with the following procedures.

Mounting the plaster mold at the laminating stand and complete the connection with the vacuum forming system after that pulling the Polyvinyalcohol (PVA) bag on the positive mold then arrange the eight layers of the perlon stockinet and fiber glass stockinet according the laminating layup ( two layers of Perlon + one layer fiber glass + two layers of Perlon + one layer fiber glass + two layers of Perlon) and again pull the outer PVA as shown in Fig. (7).
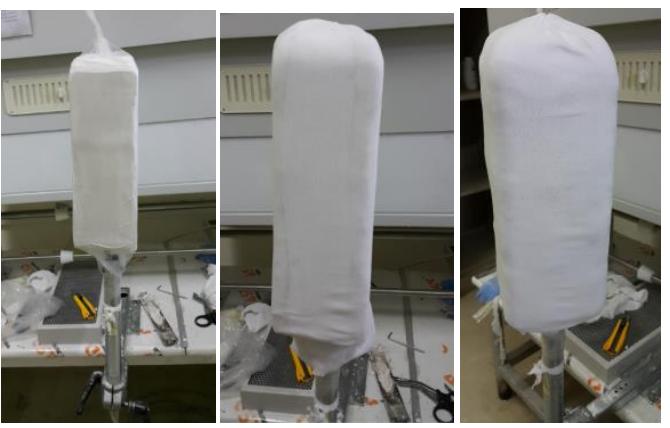

Figure (7): Arrangement of the lamination layers

Then Mixing the lamination resin 80:20 polyurethane with the hardener according the standard ratio for each 100 part of acrylic resin mixed (2-3)part of hardener [11] and then putting the resulting matrix mixture inside the outside (PVA)bag and distributing the matrix homogeneously over all area of lamination stockinet. Maintaining constant vacuum until the composite materials becomes cold and then left the resulting lamination.

2.5.3. Cutting three samples of lamination for tensile test machine (Testometric), where the process of cutting samples done in the same direction. The specimens dimension cut according to ASTM D638[12] while thickness varies according to the type of layup as shown in Fig. (8).All specimens were tested at strain rate equal to $2 \mathrm{~mm} / \mathrm{min}$. The three samples of lamination after cutting by $\mathrm{CNC}$ machine can be shown in Fig. (9).

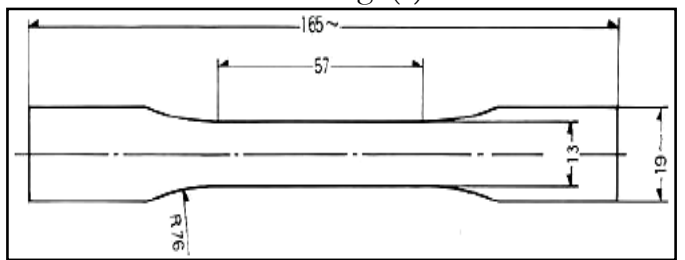

Figure (8): The dimensions of tensile specimen.

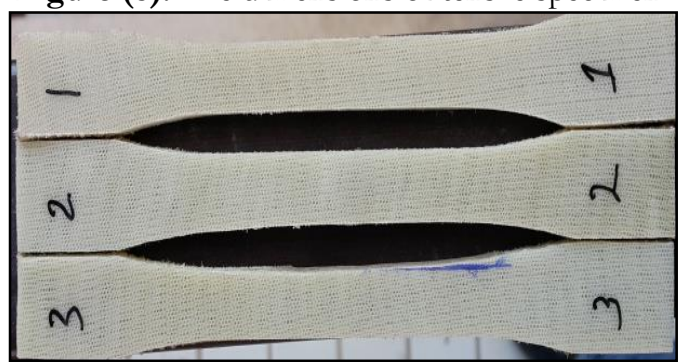

Figure (9): The three samples of lamination for tensile test 
2.5.4. Cutting six samples for fatigue test by the fatigue machine (HSM20). Samples were cut in the same direction with a dimension according to the fatigue device test. The length of fatigue spacemain $=100 \mathrm{~mm}$ and width $10 \mathrm{~mm}$ while thickness various with the type of layup as shown in Fig. (10) [13-14].

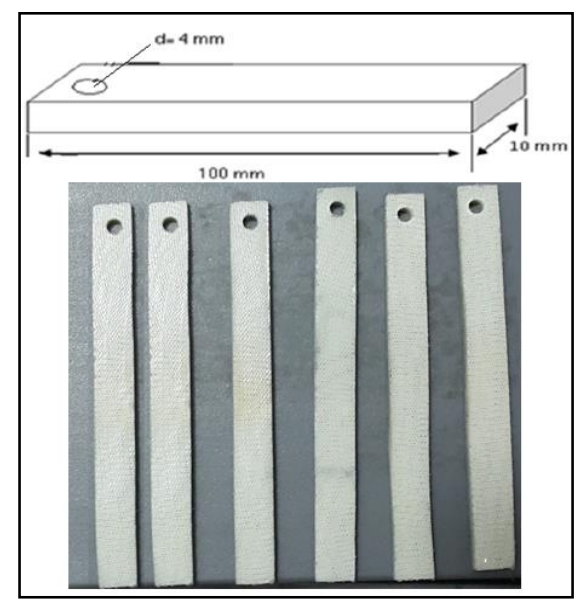

Figure (10): Fatigue test specimens and the dimensions for lamination material.

Table (3): The lamination manufactured data

\begin{tabular}{|c|c|c|}
\hline $\begin{array}{c}\text { Layer Composite } \\
\text { material }\end{array}$ & $\begin{array}{c}\text { No. of } \\
\text { layer }\end{array}$ & $\begin{array}{c}\text { Thickness } \\
\text { (mm) }\end{array}$ \\
\hline $\begin{array}{c}\text { (2Perlon+1 fiber } \\
\text { glass+2perlon+1 fiber } \\
\text { glass+2Perlon) }\end{array}$ & 8 & 2.8 \\
\hline
\end{tabular}

\section{Results and discussion}

\subsection{Cobb angle result:}

The first step in examination patient with scoliosis taking X-ray test for vertebral column as shown in Fig. (11). In this $\mathrm{x}$-ray slide show the degree of deformity deviates 40 from normal spinal position. This process simplifies posting three-point pressure correction in true region during manufacturing TLSO orthosis.

\subsection{Results of force plate test:}

The results of gait cycle test list in table (4) observation no large difference in parameters of gait cycle between left and right leg in both cases when the patient dress up orthosis and without dressing TLSO orthosis because of the patient is not suffering from any atrophy or deformity in lower limb however these very simple deference can be found in any normal person. But the clear difference can be noted in path of walking for the patient when walking without orthosis. Figure (12) shows the straight line path when the patient dressing up orthoses and how deviated path when walked without orthosis as shown in Fig. (13). The deviation in path of walking result from change center of mass for the patient as a result of lateral deformity of spinal and back while the center mass returned to a suitable position when dressing TLSO orthosis.

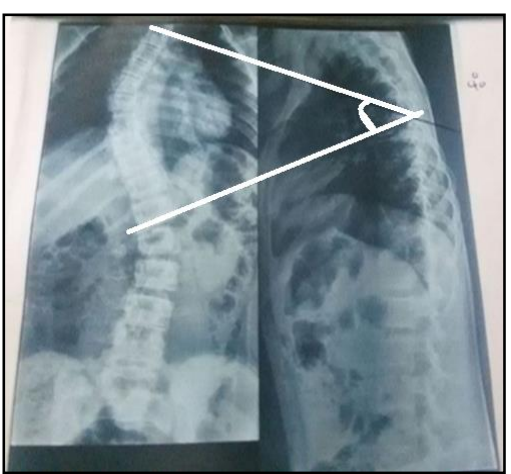

Figure (11): show the degree of deformity on x-ray slid

Table (4): Gait cycle parameters

\begin{tabular}{|c|c|c|c|}
\hline Step- Stride Table & Left & Right & Difference \\
\hline Step Time (sec) & 0.69 & 0.71 & 0.02 \\
\hline Step Length (m) & 0.54 & 0.59 & 0.05 \\
\hline Step Velocity (m/sec) & 0782 & 0.83 & 0.048 \\
\hline Step Width (m) & 11.5 & 12 & 0.5 \\
\hline Gait Cycle Table (sec) & Left & Right & Difference \\
\hline Heel contact Time & 0.79 & 0.75 & 0.04 \\
\hline Foot Flat Time & 0.2 & 0.18 & 0.02 \\
\hline Midstance Time & 0.6 & 0.58 & 0.02 \\
\hline Propulsion Time & 0.26 & 0.27 & 0.01 \\
\hline $\begin{array}{c}\text { Active Propulsion } \\
\text { Time }\end{array}$ & 0.08 & 0.05 & 0.03 \\
\hline $\begin{array}{c}\text { Passive Propulsion } \\
\text { Time }\end{array}$ & 0.18 & 0.22 & 0.04 \\
\hline
\end{tabular}

Figure (12): walk path of the walking patient when dress up orthosis

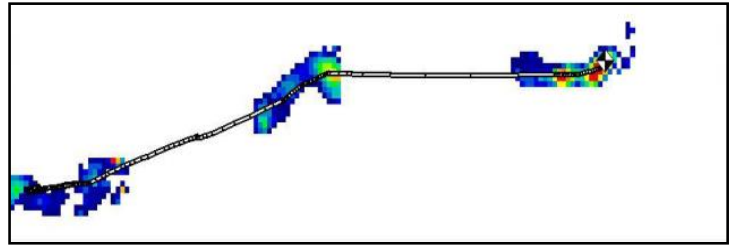

Figure (13): walk path of the walking patient without dress up orthosis

\subsection{Results of F-socket test :}

From experimental part of measuring interface pressure for different position where pressure action indicates that the maximum pressure acting at left thoracic region with $900 \mathrm{kpa}$ because it is bony region and this pressure exactly more affecting to back spinal to origin position while the minimum pressure measured at right chest $140 \mathrm{kpa}$ because of it is tissue region these reading. The values of interface pressure are summarized in table (5).

Table (5): The pressure value at contact position

\begin{tabular}{|c|c|}
\hline The region of sensor & The pressure value \\
\hline Right Iliac fossa & $250 \mathrm{kpa}$ \\
\hline Left Iliac fossa & $150 \mathrm{kpa}$ \\
\hline right chest & $140 \mathrm{kpa}$ \\
\hline Left chest & $190 \mathrm{kpa}$ \\
\hline Right waist & $150 \mathrm{kpa}$ \\
\hline Left thoracic & $900 \mathrm{kpa}$ \\
\hline
\end{tabular}




\begin{tabular}{|c|c|}
\hline Thoracic-lumbar & $280 \mathrm{kpa}$ \\
\hline Left Lumbar-sacrum & $600 \mathrm{kpa}$ \\
\hline right Lumbar-sacrum & $250 \mathrm{kpa}$ \\
\hline
\end{tabular}

\subsection{Result of tensile test}

The mechanical properties of the suggested lamination composite layer were obtained by taking the average value of three samples as illustrated in table (6) and the stress -strain curve shown in Fig. (14).

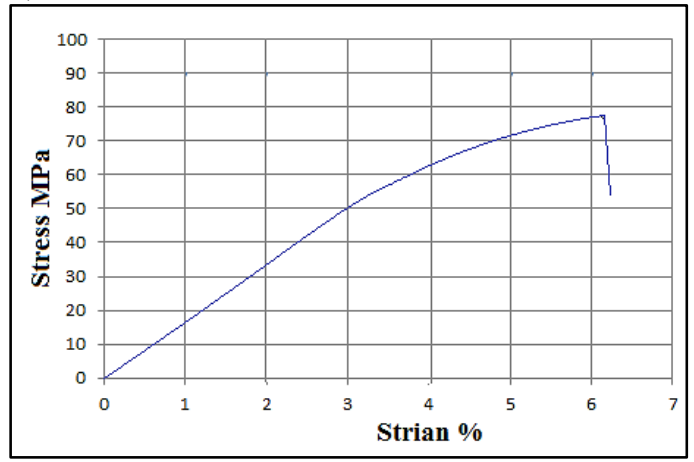

Figure (14): the stress -strain curve of the suggested lamination composite layer.

Table (6): The mechanical properties of lamination composite layer

\begin{tabular}{|c|c|c|c|}
\hline $\begin{array}{c}\text { Layer Composite } \\
\text { material }\end{array}$ & $\begin{array}{c}\sigma_{y} \\
(\mathrm{MPa})\end{array}$ & $\begin{array}{c}\sigma_{u l t} \\
(\mathrm{MPa})\end{array}$ & $\begin{array}{c}\mathrm{E} \\
(\mathrm{GPa})\end{array}$ \\
\hline $\begin{array}{c}\text { (2Perlon+1fiber } \\
\text { glass+2perlon+1fiber } \\
\text { glass+2Perlon) }\end{array}$ & 64 & 79 & 1.6 \\
\hline
\end{tabular}

\subsection{Fatigue Properties Results}

The relationship between the stress and the number of the cycle from fatigue testing gives an indication of the behavior in terms of fatigue life is illustrated in Fig. (15). These results are obtained by using specimens for each stress level. The stress endurance of suggested material equal to $27 \mathrm{MPa}$

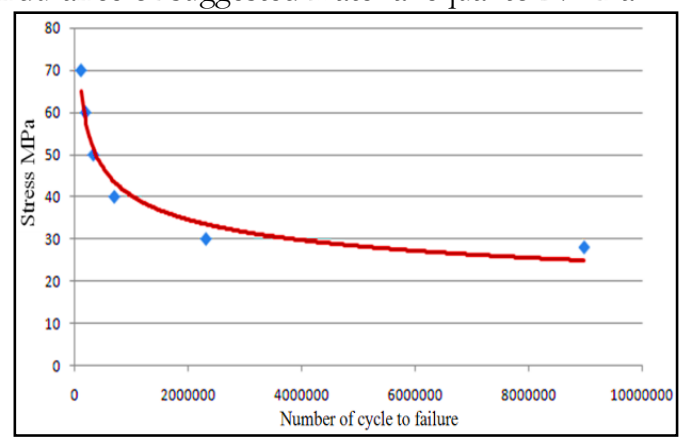

Figure (15): S-N fatigue tests curve for lamination material.

\subsection{Defining the Analysis Type and Applying Load:}

The term load includes the boundary conditions (constraints, supports, or boundary field specification), as well as other externally and internally applied loads [15-16]. The ANSYS Workbench software using in this study for analysis stresses that generated in the orthosis due to the applied correction force and interface pressure. The ANSYS software needing to a model for analysis for this reason the model of TLSO orthosis was drawn by the AutoCAD software with a dimension according to the measurement dimension of the manufacturing orthosis which is used by the patient .Finally, the applied the boundary condition of the load (interface pressure) value according to the values of and positions in F-socket test are as shown in Fig. (16).

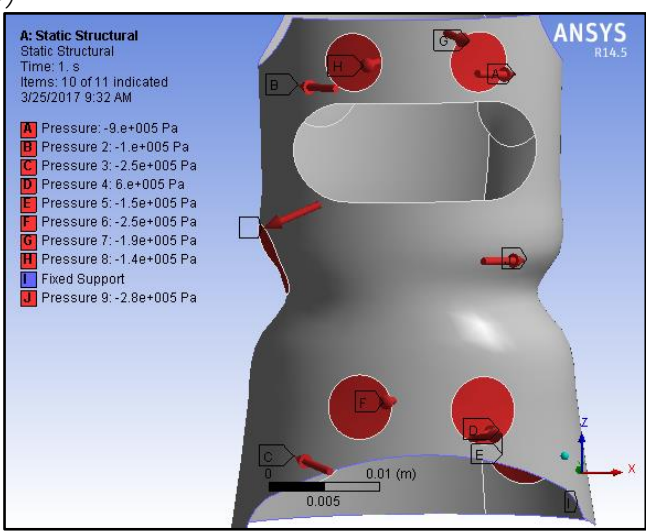

Figure (16): The model subjected to interface pressure load.

3.7. The stresses Results and discussion of TLSO model:

Figure (17) shows the general contour of Von misses for TLSO resulting from ANSYS 14.5 program with element was selected as tetrahedron (Automatic meshing).The Figure also shows that maximum value of stress was recorded at left thoracic region with $2.816 \mathrm{MPa}$ due to the maximum interface pressure at this point and the loading boundary condition. Note that the maximum value of stress generated in the TLSO orthosis due to applied the corrective force is far from the limit of the failure for the polypropylene made of the orthosis. This confirms the strength of the orthosis and its success in carrying out the applied forces. From the static stress analysis, the lamination material layers is the best material than polypropylene can be selected in manufacturing because there is a big gap between the values of the maximum stress $(2.81 \mathrm{MPa})$ to the value of yield strength $(62.3 \mathrm{MPa})$ of that material. To compute the safety factor of fatigue. The safety factor for lamination TLSO model passed in design, for fatigue safety factor was about (1.37), which is safe in design as shown in Fig. (18). The safety factor for fatigue will be safe in design if the safety factor about or more than (1.25) [17].

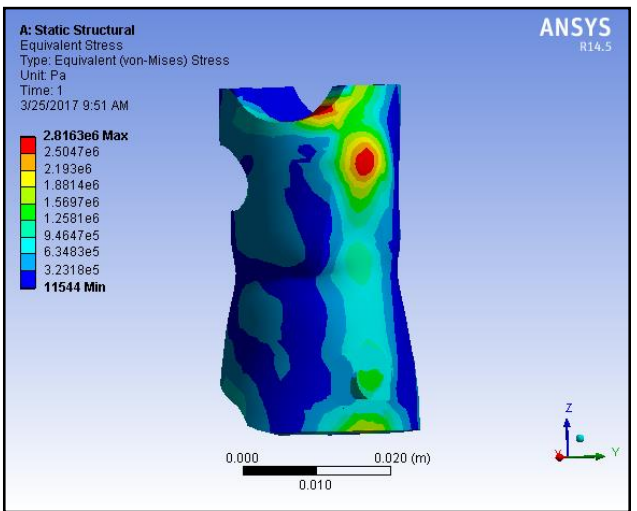




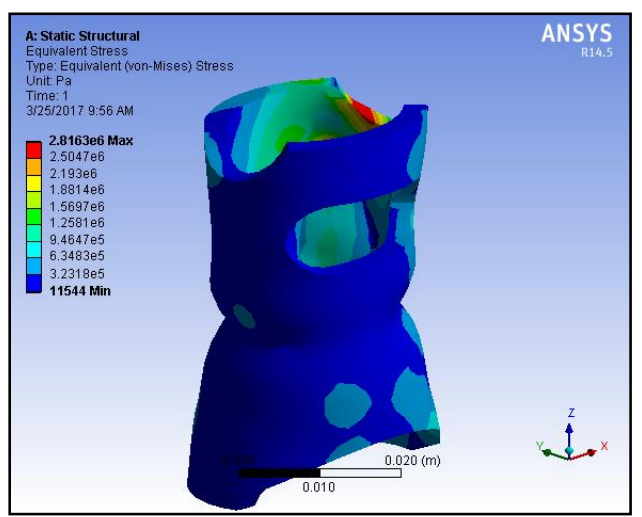

Figure (17): Von-Mises stress of TLSO model.

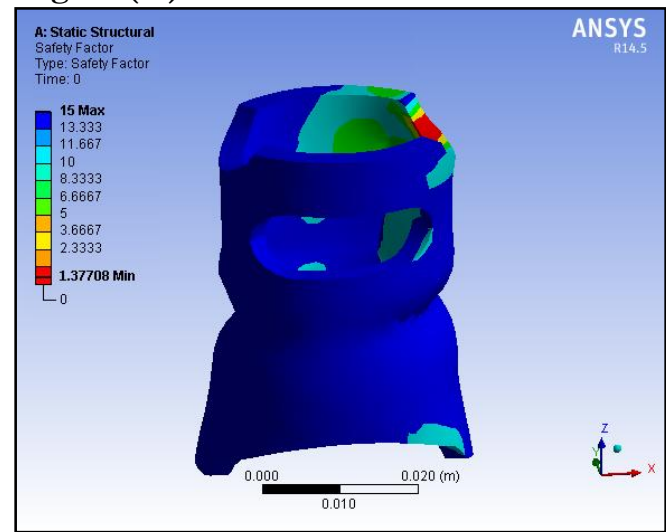

Figure (18): The Safety Factor for Fatigue Lamination

\section{Conclusions:}

The following conclusions are drawn from the results obtained in this work

1- Use X-rays to determine the exact location for applied the correction force.

2- When analyzing the walking cycle of the patient before wearing the orthosis, it was noted that the walking path deviates from the straight line While the walking path returns to the straight line when wearing the brace

3-No deference in gait cycle phases because of patient not suffering from any atrophy or deformity in lower limb.

4- Maximum pressure recorded at left thoracic region with $900 \mathrm{kpa}$ to correct spinal deformity while the minimum pressure recorded at right chest with $140 \mathrm{kpa}$ because of it is tissue region.

5- Maximum value of stress was recorded at the left thoracic region with $2.81 \mathrm{mpa}$ due to Maximum interface pressure at this point.

6-For lamination material layers the mechanical properties of orthosis are improved clearly.

\section{References}

[1] Fahad .M.Kadhim ,Ayad .M.Takhakh and Jumaa.S.chiad,"Vibration Measurment and analysis of knee Ankle foot orthosis for both metal and plastic KAFO type",ASME International Mechanical Engineering Congress and exposition, USA.

[2].Edelstein, J. E.,"Orthoses for Spinal Pain. In B. Goldberg and J. D. Hsu (Eds.), Atlas of Orthoses and Assistive Devices" ,3rd ed., pp. 243-250,1996.
[3]. Miller, N. H.,"Cause and natural history of adolescent idiopathic scoliosis" Orthopedic Clinics of North America, 30 (3): 343-352,1999.

[4] Jaremko, J. L., Poncet, P., Ronsky, J., Harder, J., Dansereau, J., Labelle, H. \& Zernicke, R. F.,"Estimation of spinal deformity in scoliosis from torso surface cross sections," Spine, 26 (14): 1583$1591,2001$.

[5] Roach, J. W.,"Adolescent idiopathic scoliosis," Orthopedic Clinics of North America, 30 (3): 353365,1999 .

[6] Flanagan, P., Gavin, T. M., Gavin, D. Q., \& Patwardhan, A. G., Spinal orthoses. In M. Lusardi \& C. Nielsen (Eds.), Orthotics and Prosthetics in Rehabilitation,pp. 231-252, 2000.

[7]. Chase, A. P., Bader, D. L., \& Houghton, G.R.,"The biomechanical effectiveness of the Boston brace in the management of adolescent idiopathic scoliosis". Spine, 14(6), 636-642, 1989.

[8].Ayad M. Takhakh, Fahad M. Kadhim, Jumaa S. Chiad,"Vibration Measurement And Analysis Of Knee-Ankle-Foot Orthosis (Kafo) Plastic-Metal Type", Journal of Engineering and Development, Vol. 17, No.6 , ISSN 1813-7822, 2013.

[9]. Kadhim K. Resan, Akeel Zeki," Design and Analysis of Knee Ankle Foot Orthosis (KAFO) for Paraplegia Person", Eng. \& Tech. Journal, Vol.31, No.8, 2013.

[10] Tekscan User Manual,2010.

[11]. Ottobock quality for life " orthotic- prosthetic materials catalog",2007

[12].American Society for Testing and Materials International "Standard Test Method for Tensile Properties of Plastics" D 638, 2000.

[13] Ayad M. Takhakh, Raied Z. Alfay, Abdul Rahim K. Abid Ali, 'Effect of Ta addition on hardness and wear resist of $\mathrm{Cu}-\mathrm{Al}-\mathrm{Ni}$ shape memory alloy fabricated by powder metallurgy' BEIAC 2013-2013 IEEE Business Engineering and Industrial Applications Colloquium, 2013.

[14].Alternating Bending Fatigue Machine Instruction Manual HSM20.

[15] Fahad M. Kadhim, Jumaa S. Chiad, Ayad M.Takhakh,( 2018) 'Design And Manufacturing Knee Joint for Smart Transfemoral Prosthetic', IOP Conference Series: Materials Science and Engineering, International Conference on Materials Engineering and Science, Vol. 454.

[16]. Ayad M. Takhakh, Jumaa S. Chiad, Fahad M. Kadhim ， (2014)," Vibration Measurement and Analysis of knee-Ankle-Foot Orthosis (KAFO) Metal-Metal type", Journal of Engineering Baghdad University Vol.20, pp. 136-149.

[17].Brett A. Miller, (2002), "Failure Analysis and Prevention, Fatigue Failures", ASM International Handbook. Vol. 11, P 1470. 